\title{
Liver Injury Induced by Levothyroxine in a Patient with Primary Hypothyroidism
}

\author{
Tomotaka Kawakami ${ }^{1}$, Atsushi Tanaka ${ }^{1}$, Shinichiro Negoro ${ }^{1}$, Yoshihiko Morisawa ${ }^{1}$, \\ Masaki Mikami ${ }^{1}$, Makoto Hojo ${ }^{1}$, Takatsugu Yamamoto ${ }^{1}$, Satoko Uegaki ${ }^{1}$, Mitsuhiko Aiso ${ }^{1}$, \\ Takahiro Kawasaki ${ }^{1}$, Taro Ishii ${ }^{1}$, Yasushi Kuyama ${ }^{1}$, Toshio Fukusato ${ }^{2}$ and Hajime Takikawa ${ }^{1}$
}

\begin{abstract}
We report a patient with primary hypothyroidism, who developed hepatocellular injury due to levothyroxine, synthetic thyroxine. A 63-year-old male was admitted to our hospital due to elevation of liver enzymes. The patient was diagnosed as having hypothyroidism and had been treated with levothyroxine for almost two months until admission. Drug-induced liver injury induced due to levothyroxine was suspected and liver enzymes were rapidly decreased after discontinuation of levothyroxine and dried thyroid powder, also containing thyroxine. Synthetic triiodothyronine, the deiodinated form of levothyroxine was administered instead, and was well tolerated by the patient. The drug-induced lymphocyte stimulation test (DLST) using levothyroxine was negative. Since triiodothyronine which structurally resembles levothyroxine did not cause liver injury, and DLST using levothyroxine was negative, it is unlikely that levothyroxine itself was targeted by the immune system. Rather, we assume that the complex of levothyroxine as the hapten and liver-related macromolecules in the body as the carrier might have acquired antigenecity in this patient and subsequently resulted in liver injury.
\end{abstract}

Key words: levothyroxine, drug-induced liver injury

(DOI: 10.2169/internalmedicine.46.0086)

\section{Introduction}

Primary hypothyroidism, mainly caused by Hashimoto's thyroiditis, is mainly treated with replacement of thyroid hormones, especially oral administration of levothyroxine, i. e. synthetic thyroxine $\left(T_{4}\right)(1)$. The use of levothyroxine for primary hypothyroidism has been well justified $(2,3)$, since levothyroxine, peripherally metabolized into triiodothyronine $\left(\mathrm{T}_{3}\right)$ through deiodination, can produce and maintain the proper amount of $\mathrm{T}_{3}$ required under physiologic control (1). In general, levothyroxine is safe and well tolerated by patients, except for the possibility of developing osteoporosis in postmenopausal patients with excessive doses (1). However, it has been known that administration of levothyroxine could cause liver injury, although scarcely reported (4-6). Recently we encountered a male patient with primary hypo- thyroidism, who developed liver injury due to levothyroxine.

\section{Case Report}

In October 2005, a 63-year-old male visited our hospital because of facial edema. Although there was a history of excess intake of alcohol beverage for 42 years, he quit drinking alcohol 4 months before his visit. On physical examination enlarged thyroid without tenderness was palpable, and facial and peripheral edema was noticed. Blood examination was compatible with primary hypothyroidism; serum levels of free $\mathrm{T}_{3}$ and $\mathrm{T}_{4}$ were decreased at $0.6 \mathrm{pg} / \mathrm{ml}$ and $0.1 \mathrm{ng} / \mathrm{dl}$, respectively, and, by contrast, the serum level of thyroid stimulating hormone (TSH) was remarkably increased to $317.9 \mu \mathrm{IU} / \mathrm{ml}$. Both antithyroglobulin antibody and antithyroid peroxidase antibody were seropositive at $10.0 \mathrm{U} / \mathrm{ml}$ and $900.0 \mathrm{U} / \mathrm{ml}$, respectively. Blood chemistry also demonstrated

${ }^{1}$ Department of Medicine, Teikyo University School of Medicine, Tokyo and ${ }^{2}$ Department of Pathology, Teikyo University School of Medicine, Tokyo

Received for publication February 7, 2007; Accepted for publication April 17, 2007

Correspondence to Dr. Atsushi Tanaka, a-tanaka@med.teikyo-u.ac.jp 


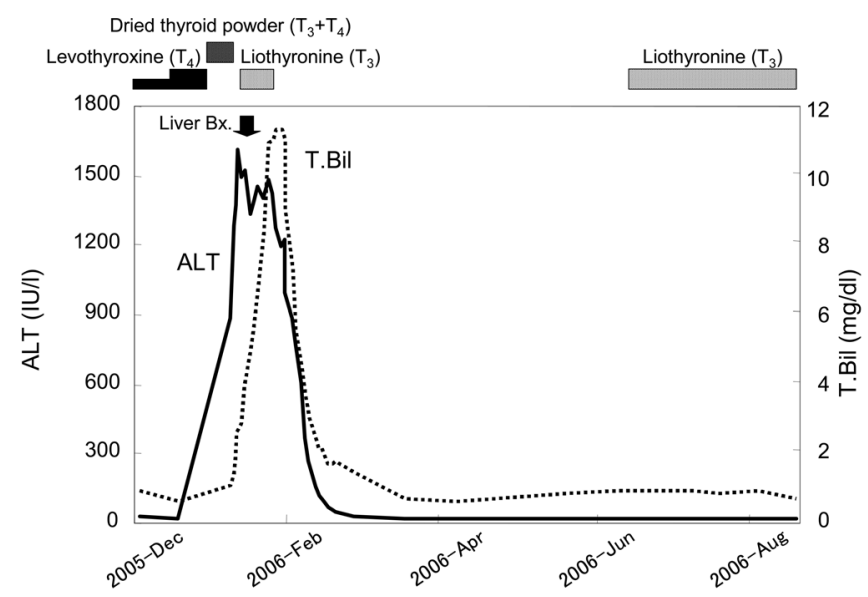

Figure 1. The clinical course of the present case after initiation of replacement therapy with levothyroxine.

elevation of total cholesterol, $258 \mathrm{mg} / \mathrm{dl}$, aspartate aminotransferase (AST), $52 \mathrm{IU} / \mathrm{l}$, creatinine kinase, 1,835 IU/l, and a normal level of alanine aminotransferase (ALT), $20 \mathrm{IU} / \mathrm{l}$; all of them were coincident with hypothyroidism. Ultrasonogram and CT scan of the neck demonstrated diffusely enlarged thyroid, without any nodularity. Thus, the diagnosis of primary hypothyroidism was made, and oral replacement therapy with $25 \mathrm{mg}$ /day of levothyroxine was initiated on December 15, 2005, and the dosage was increased to $50 \mathrm{mg}$ /day on January 5, 2006, 22 days later.

However, blood examination at a regular visit on February 2, 2006, almost two months after initiation of replacement therapy with levothyroxine, demonstrated elevation of liver enzymes, AST $670 \mathrm{IU} / 1$ and ALT 884 IU/l, and the patient was admitted for further evaluation and treatment on that day. On admission, the consciousness was clear, and no jaundice was noted on the skin or conjuctiva. Thyroid was not palpable at this time. Hepatosplenomegaly was not observed, either. Complete blood counts and other blood chemistry were as follows; white blood cell $6,600 / \mathrm{ml}$ (eosinophil 16\%), hemoglobin $13.3 \mathrm{~g} / \mathrm{dl}$, platelet counts $217,000 / \mathrm{mm}^{3}$, albumin $4.1 \mathrm{~g} / \mathrm{dl}$, total bilirubin $1.5 \mathrm{mg} / \mathrm{dl}$, direct bilirubin $0.7 \mathrm{mg} / \mathrm{dl}$, alkaline phosphatase $458 \mathrm{IU} / \mathrm{l}$, gamma glutamyltranspeptidase 252 IU/l. Erythrocyte sedimentation rate was $12 \mathrm{~mm} / \mathrm{hr}$, slightly elevated. Blood markers indicating viral and autoimmune acute liver injury, including viral markers for hepatitis $\mathrm{A} / \mathrm{B} / \mathrm{C}$ virus, cytomegalovirus, Epstein Barr virus, and autoantibodies were negative. Although serum TSH level was $150.6 \mu \mathrm{IU} / \mathrm{ml}$, still high on admission, serum free $\mathrm{T}_{3}$ and $\mathrm{T}_{4}$ were within normal limit, $2.5 \mathrm{pg} / \mathrm{ml}$ and $0.8 \mathrm{ng} / \mathrm{dl}$, respectively. Therefore, liver injury induced by hyperthyroidism due to overdose of levothyroxine was denied.

The clinical course after admission is shown in Fig. 1. Since drug-induced liver injury caused by levothyroxine was suggested as a possible etiology on admission, the administration of levothyroxine was discontinued soon after admission and we administered dried thyroid powder containing both natural $\mathrm{T}_{3}$ and $\mathrm{T}_{4}$ instead. However, the elevation of
ALT continued and jaundice developed along with administration of dried thyroid powder, and the results of blood test on admission suggested no other etiology of liver injury, as shown above. In addition, we performed liver biopsy for histological evaluation on the 12th hospital day. Liver histologies demonstrated marked infiltration of inflammatory cells, consisting of considerable eosinophils, within and in the vicinity of enlarged and edematous portal tracts (Fig. 2a). Focal necrosis and infiltration of eosinophils were observed within liver parenchyma (Fig. 2a), without predominancy in centrilobular zones (Fig. 2b). Taken together, we made a diagnosis as levothyroxine-induced liver injury, and changed replacement therapy from dried thyroid powder to liothyronine, synthetic $\mathrm{T}_{3}$, at the 17 th hospital day.

While the serum value of ALT decreased after discontinuation of dried thyroid powder, total bilirubin as well as jaundice became exacerbated, as shown in Fig. 1. Since the possibility that liothyronine also contributed to the liver injury was not excluded, liothyronine was discontinued at the 27th hospital day. Thereafter, liver enzymes and jaundice rapidly disappeared and the patient was discharged soon.

Meanwhile, hypothyroidism had not been treated at all after discharge and symptoms including peripheral edema developed again. Hence we administered liothyronine as a replacement therapy, and no liver injury has noted subsequently (Fig. 1). According to the criteria for drug-induced liver injury proposed by the Digestive Disease Week Japan in 2004, the score was 9, suggesting the causality of levothyroxine was 'highly probable' (7). Therefore, we finally concluded that only levothyroxine, not liothyronine, was responsible for liver injury.

During his admission, we performed a drug-induced lymphocyte stimulation test (DLST) $(8,9)$, using levothyroxine, dried thyroid powder, and liothyronine as candidate responsible drugs. The results are shown in Table 1 and none of them demonstrated a positive response. 

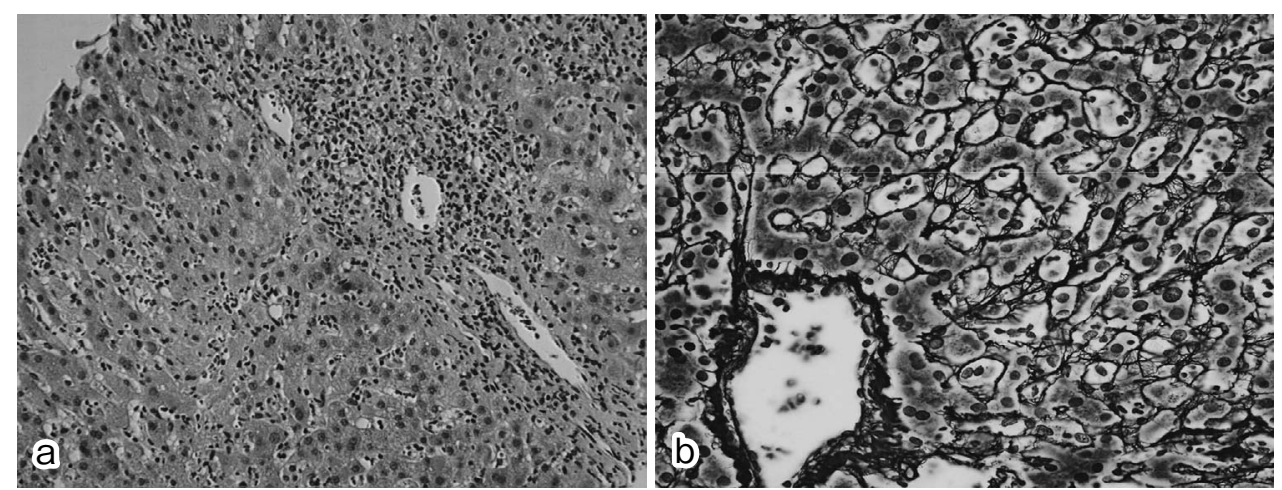

Figure 2. Histopathological studies of the biopsied specimens of the liver demonstrated marked infiltration of inflammatory cells, consisting of considerable eosinophils, within and in the vicinity of the enlarged and edematous portal tracts. Mild proliferation of bile ducts and derangement of cholangiocytes were also seen. Focal necrosis and infiltration of eosinophils were observed within liver parenchyma (a, hematoxylin eosin stain, $\times 200$ ), even though necrosis and degeneration of hepatocytes was not remarkable in centrilobular zones $(b$, silver stain, $\times 400)$.

Table 1. The Results of Drug-Induced Lymphocyte Stimulation Test (DLST)

\begin{tabular}{|l|l|l|l|}
\hline Drug* & & Values (cpm) & Stimulation index (\%)** \\
\hline \multirow{2}{*}{ Levothyroxine } & $\mathrm{pt}$ & 259 & \multirow{2}{*}{87} \\
\cline { 2 - 3 }$\left(\right.$ Synthetic $\left.\mathrm{T}_{4}\right)$ & control & 295 & \\
\hline \multirow{2}{*}{ Dried thyroid powder } & $\mathrm{pt}$ & 291 & \multirow{2}{*}{98} \\
\cline { 2 - 3 }$\left(\mathrm{T}_{3}\right.$ and $\left.\mathrm{T}_{4}\right)$ & control & 295 & \\
\hline \multirow{2}{*}{ Liothyronine } & pt & 215 & \multirow{2}{*}{114} \\
\cline { 2 - 3 }$\left(\right.$ Synthetic $\left.\mathrm{T}_{3}\right)$ & control & 188 & \\
\hline
\end{tabular}

* A dose per day of each drug (Levothyroxine $50 \mu \mathrm{g}$, dried thyroid powder $40 \mathrm{mg}$,

liothyronine $25 \mu \mathrm{g}$ ) was diluted in $190 \mathrm{ml}$ of phosphate buffer saline and used for assay

with serial dilutions. Values were counted at $3^{-4}$ dilution for levothyroxine and

liothyronine, and $3^{-3}$ for dried thyroid powder.

** The results of DLST are considered to be positive, if the S.I. is greater than $181 \%$.

\section{Discussion}

For the treatment of hypothyroidism, either primary or central, levothyroxine, synthetic $\mathrm{T}_{4}$, is primarily recommended $(2,3)$ due to several reasons. Orally administered levothyroxine is absorbed relatively slowly and equilibrates rapidly in its distribution volume, therefore avoiding large postabsorptive perturbations in free $\mathrm{T}_{4}$ levels (1). In addition, levothyroxine is metabolized to its active form $\mathrm{T}_{3}$ peripherally and thus it is rational to supply the "prohormone", which is activated by physiologically regulated mechanisms (1). In the current case, levothyroxine, administered as a replacement therapy for hypothyroidism, caused liver injury. Dried thyroid powder, mixture of $\mathrm{T}_{3}$ and $\mathrm{T}_{4}$, also augmented the elevation of liver enzymes, while liothyronine (synthetic $\mathrm{T}_{3}$ ) did not demonstrate any liver damage.

In general, the replacement with synthetic $\mathrm{T}_{4}$ for hypothyroidism increases the oxygen demand of hepatocytes. Thus, it would be possible to assume that liver injury in the current case developed due to relative ischemia of the liver, i.e. relatively reduced supply of oxygen to hepatocytes after oxygen demand was enhanced with replacement of thyroid hormone. However, if this would be the case, necrosis of hepatocytes would be mainly located at zone 3 , the periportal area. In this case, focal necrosis and infiltration of eosinophils were mainly observed within liver parenchyma, even though also seen in the vicinity of the portal tracts. Therefore, it is implausible that ischemia due to replacement of thyroid hormone would be the reason for liver injury.

It should be considered how liver injury was caused by levothyroxine, identical to $T_{4}$, a low weight and generally present molecule in a body. Clearly, it is very unlikely that levothyroxine itself is targeted and recognized by $\mathrm{T}$ lymphocytes through presentation as antigens by antigen-presenting cells (APCs). This is supported by the fact that DLST, in which levothyroxine was added to mononuclear cells preparation of the patient $(8,9)$, showed negative results. In the demonstrated case, levothyroxine induced hepatocellular injury, while liothyronine was well tolerable without any elevation of liver enzymes. Since the molecular structures of levothyroxine and liothyronine are quite similar, conservation of liothyronine from liver injury also indicates that primary structure of levothyroxine was not targeted by the immune response.

Alternatively, we assumed that levothyroxine operated as a hapten. A complex of hapten and carrier protein would be incorporated and digested by APCs, and part of the complex would be recognized by $\mathrm{T}$ lymphocytes, leading to liver injury. In general, levothyroxine is bound to albumin, thyroxine binding globulin and transthyretin in sera (2); however, presumably carrier proteins in the current case may be closely related to the liver, and thus far liver injury devel- 
oped. Interestingly, the safety of liothyronine in cases with levothyroxine-induced liver injury is a common feature among previous reports (4-6). Similarly, liothyronine caused no skin lesion to develop and was safely administered in a case with drug eruption caused by levothyroxine (10). It is likely that conformational epitopes derived from a complex of levothyroxine, not liothyronine, and carrier protein may be easily recognized by immune system in genetically sus- ceptible individuals.

In conclusion, we reported a case with levothyroxineinduced liver injury. Since it is unlikely that levothyroxine itself was a target molecule of $\mathrm{T}$ lymphocytes, the diagnostic value of DLST might be limited for this drug. When liver injury develops during replacement therapy for patients with hypothyroidism, drug-induced liver injury should not be overlooked.

\section{References}

1. Larsen P, Davies T. Hypothyroidism and thyroiditis. in: Williams Textbook of Endocrinology Larsen P, Kronenberg H, Melmed S, Polonsky K, Eds. Saunders, Philadelphia 2003: 331-373.

2. Mandel S, Brent G, Larsen P. Levothyroxine therapy in patients with thyroid disease. Ann Intern Med 119: 492-502, 1993.

3. Toft A. Thyroxine therapy. N Engl J Med 331: 174-180, 1994.

4. Inui A, Ishikawa K, Mizuno N, Oimomi M, Baba S. Case of Hashimoto's disease with thyroxine induced allergic hepatitis. Nippon Naika Gakkai Zasshi 72: 1407-1413, 1983 (in Japanese, abstract in English).

5. Shibata H, Hayakawa H, Hirukawa M, Tadokoro K, Ogata E. Hypersensitivity caused by synthetic thyroid hormones in a hypothyroid patient with Hashimoto's thyroiditis. Arch Intern Med 146: 1624-1625, 1986

6. Ohmori M, Harada K, Tsuruoka S, Sugimoto K, Kobayashi E, Fu- jimura A. Levothyroxine-induced liver dysfunction in a primary hypothyroid patient. Endocr J 46: 579-583, 1999.

7. Takikawa H, Onji M. A proposal of the diagnostic scale of druginduced liver injury. Hepatol Res 32: 250-251, 2005.

8. Maria V, Pinto L, Victorino R. Lymphocyte reactivity to exvivo drug antigens in drug-induced hepatitis. J Hepatol 21: 151-158, 1994.

9. Maria V, Victorino R. Diagnostic value of specific T cell reactivity to drugs in 95 cases of drug induced liver injury. Gut 41: 534540, 1997.

10. Matsuno M, Sohmiya M, Nishiki M, Ohguni S, Kato Y. A case of chronic thyroiditis associated with drug eruption induced by levothyroxine sodium (Thyradin S). Folia Endocrinol 73: 617-622, 1997 (in Japanese, abstract in English).

(C) 2007 The Japanese Society of Internal Medicine http://www.naika.or.jp/imindex.html 